\title{
Thiazole-amino acids: influence of thiazole ring on conformational properties of amino acid residues
}

\author{
Monika Staś ${ }^{1,2}$ (D) Małgorzata A. Broda ${ }^{1}$ (i) $\cdot$ Dawid Siodłak $^{1}$ (i)
}

Received: 5 December 2020 / Accepted: 29 March 2021 / Published online: 10 April 2021

(c) The Author(s) 2021

\begin{abstract}
Post-translational modified thiazole-amino acid (Xaa-Tzl) residues have been found in macrocyclic peptides (e.g., thiopeptides and cyanobactins), which mostly inhibit protein synthesis in Gram + bacteria. Conformational study of the series of model compounds containing this structural motif with alanine, dehydroalanine, dehydrobutyrine and dehydrophenylalanine were performed using DFT method in various environments. The solid-state crystal structure conformations of thiazole-amino acid residues retrieved from the Cambridge Structural Database were also analysed. The studied structural units tend to adopt the unique semi-extended $\beta 2$ conformation; which is stabilised mainly by $\mathrm{N}-\mathrm{H} \cdots \mathrm{N}_{\text {Tzl }}$ hydrogen bond, and for dehydroamino acids also by $\pi$-electron conjugation. The conformational preferences of amino acids with a thiazole ring were compared with oxazole analogues and the role of the sulfur atom in stabilising the conformations of studied peptides was discussed.
\end{abstract}

Keywords Thiazole $\cdot$ Non-standard amino acids $\cdot$ Conformational analysis $\cdot$ Ramachandran map $\cdot$ Hydrogen bond $\cdot$ DFT

\section{Introduction}

The biological activity and metal-binding properties of proteins and peptides depend on their conformation (Giri Rao and Gosavi 2016). The capability of changing ligand conformation to improve binding affinity in proteins is one of the biomolecular engineering tools crucial for drug discovery and design (Lassila 2010; Gagné et al. 2012; Boehr et al. 2018; Ding et al. 2020; Aguesseau-Kondrotas et al. 2019). Mapping the conformational space of small peptide fragments is also an important prerequisite in decoding the protein folding process and understanding protein structure (Culka et al. 2019; Culka and Rulíšek 2019, 2020; Ganesan

Handling editor: S. C. E. Tosatto.

Monika Staś

plgmonika691@gmail.com; mstas@uni.opole.pl

$\triangle$ Dawid Siodłak

dsiodlak@uni.opole.pl

1 Faculty of Chemistry, University of Opole, 45-052 Opole, Poland

2 Institute of Organic Chemistry and Biochemistry of the Czech Academy of Science, Flemingovo Náměstí 2, 16610 Praha 6, Czech Republic and Paranthaman 2020; Chahkandi et al. 2014). According to the funnel landscape theory, the side chains are primarily responsible for folding diversity. On the contrary, the backbone-based theory postulates that the universality of the osmolyte effect points to the conclusion that self-organisation takes place mainly in the main chain (Rose et al. 2006; Dill et al. 2008). A recent ab initio study confirmed that such a small unit as tripeptides fragments composed of standard amino acids already exhibit a small tendency to adopt a particular secondary structure (helical or extended) (Culka et al. 2019). Regardless of the chosen theory, it is sure that the conformational preferences of amino acid residues or short peptide fragments have a high impact on the overall secondary structure. Studies on unusual (or non-native) amino acid residues can further deepen our insight in the understanding native structure of peptides, predict it and/or design peptides with specific characteristics. Of special interest are azolebased peptides, due to their unique conformation and high propensity to metal complexation such as copper, calcium, or silver (Bertram and Pattenden 2007; Cusack et al. 2002; Gahan and Cusack 2018).

Previous studies have shown that modifications of peptide main chain or side chain as $N$-methylation (Siodłak et al. 2006, 2008, 2012; Broda et al. 2005, 2009), $C$-terminal ester bond (Siodłak et al. 2010, 2011; Siodłak and Janicki 2010), 
dehydration of side chain (Buczek et al. 2014), cyclization (Staś et al. 2016a), and many more (Jwad et al. 2020; Gil et al. 2009; Paranthaman 2018) have a considerable influence on preferred conformation. This includes the introduction of a five-membered heterocycle, such as oxazole (Siodłak et al. 2014a; Staś et al. 2016a, b) or thiazole, into a peptide main chain as an isosteric replacement of amide group. Peptides that contain heterocyclic amide isosteres are usually more rigid than the corresponding homodetic cyclic peptide (Jwad et al. 2020; Abbenante et al. 1996). Their aromatic character forces the ring atoms into the coplanar arrangement. As a consequence, the flexibility of the peptide main chain decreases, and the overall conformation is more constrained. It often changes the intra- and intermolecular interactions pattern and affects the overall properties of the compound (Schärfer et al. 2013; Reid et al. 2014; Kheirjou et al. 2014).

In nature, heterorings are obtained in post-translational modifications from standard amino acid residues such as threonine, serine, and cysteine (Metelev and Ghilarov 2014). They occur in highly modified macrocyclic peptides; thiopeptides or cyanobactins (Bagley et al. 2005; Jin 2011). In many cases, these compounds have promising anti-tumour, anti-bacterial, or anti-malaria activities (Davyt and Serra 2010). Residues with thiazole ring have the most diverse side chains among other rings (thiazoline, oxazole, and oxazoline). Literature survey reveals that in natural compounds they can be found as thiazole-glycine (Kai et al. 2012; Debono et al. 1992; Engelhardt et al. 2010; Jüttner et al. 2001), alanine (Kai et al. 2012; Bagley et al. 2000; Castro Rodríguez et al. 2002; Engelhardt et al. 2010), valine (Bagley et al. 2005; Hughes and Moody 2007; Bertram and Pattenden 2007; Jüttner et al. 2001), serine (Zhang et al. 2009), methionine (Jüttner et al. 2001), threonine (Davyt and Serra 2010), leucine (Davyt and Serra 2010), isoleucine (Jüttner et al. 2001), asparagine (Zhang and Liu 2013; Young and Walsh 2011), phenylalanine (Davyt and Serra 2010), dehydroalanine (Aoki et al. 1991), dehydrobutyrine (Kai et al. 2012; Walsh et al. 2010) and other (Bagley et al. 2005; Jin 2011). The important feature of the thiazole ring is the presence of the $s p^{2}$ sulfur atom which has a larger size than carbon, nitrogen, or oxygen, and its ability to engage in donating $n_{\mathrm{o}} \rightarrow \sigma^{*}$ interaction ( $\sigma$-holes) with the lone pairs of neighbouring heteroatoms. It can lead to conformational and steric effects unique for S-containing heterocycles (Dudkin 2012). Sulfur atom in a heteroaromatic ring may also act as a Lewis acid or electrophile and despite its electronegativity, interacts with electron donors, particularly with oxygen or nitrogen atoms, and $\pi$-systems. Sulfur-containing heterocycles may also participate in attractive non-bonding interactions that control the molecular conformation. This may improve binding affinity, independently on ligand-target contacts, and enhance selectivity; at the same time mitigating off-target toxicity and/or metabolic modification. Examples can be found in the study of Beno and co-workers (Beno et al. 2015). The energy of $S \cdots O$ interaction between thiophene or thiazole and carbonyl oxygen is comparable to a typical hydrogen bond (Murray et al. 2008; Chahkandi and Chahkandi 2020; Aliakbar Tehrani and Fattahi 2013). Thiazole derivatives are widely used in pharma industry (Ilardi et al. 2014). Sulfur-containing ligands improve the inhibitor activity for thrombosis Factor Xa (FXa) and selectivity as for MMP-13 inhibitors (Metalloproteinase) therapeutically useful for curing osteoarthritis (Zhang et al. 2015). Replacement of the amide group by 5-membered heterocycles (thiazole, oxazole, and imidazole) leads to a stronger interaction between the ligand and $\mathrm{Mg}^{2+}$ ions of HIV-1 integrase (Le et al. 2010).

The aim of this work is to provide an in-depth analysis of conformational properties of thiazole-containing amino acids (Xaa-Tzl), where the thiazole ring is in place of the C-terminal amide group (Fig. 1). The simplest and most common naturally occurring residues with thiazole ring were chosen; alanine (Ala-Tzl), dehydroalanine ( $\Delta$ Ala-Tzl), and $\mathrm{Z}$-dehydrobutyrine $((\mathrm{Z})-\Delta \mathrm{Abu}-\mathrm{Tzl})$. In addition, dehydrophenylalanine ( $\Delta \mathrm{Phe}-\mathrm{Tzl})$ was analysed, the most often studied dehydroamino acid, due to the easily accessible synthesis of both geometric isomers $Z$ and $E$. In particular, thiazole- $\alpha, \beta-$ dehydroamino acid residues are interesting as they combine together two structural motifs; the double bond between $\alpha$ and $\beta$ carbon atoms and thiazole ring (Siodłak 2015; Jaremko et al. 2013). The results obtained from DFT study were confronted with the data for crystal structures presented in the Cambridge Structural Data Base (Groom et al. 2016). The comparison with conformational properties of oxazole and oxazoline amino acid analogues is also mentioned.

\section{Computational details}

The conformational properties of the following molecules: Ac-L-Ala-Tzl(4-Me) (1), Ac- $\Delta$ Ala-Tzl(4-Me) (2), Ac-(Z)- $\Delta$ Abu-Tzl(4-Me) (3), Ac-(Z)- $\Delta$ Phe-Tzl(4-Me)
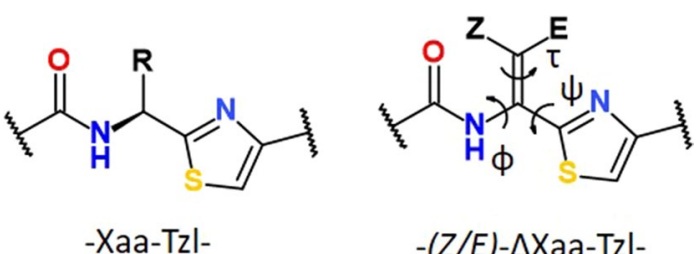

$-(Z / E)-\Delta X a a-T z \mid-$

Fig. 1 Schematic formula of thiazole-amino acid (-Xaa-Tzl-) and thiazole- $\alpha, \beta-$ dehydroamino acid residues (-(Z/E) $-\Delta$ Xaa-Tzl-) 
(4), and Ac- $(E)-\Delta \mathrm{Phe}-\mathrm{Tzl}(4-\mathrm{Me})(5)$ were modelled by DFT method (Fig. 2).

Conformational maps for Ac-L-Ala-Tzl(4-Me) (1) and Ac- $\Delta$ Ala-Tzl(4-Me) (2) in gas phase (partial optimization with constrained torsion angles, $\varphi$, and $\psi$, change with the step of 30 degrees), chloroform, and water (single-point calculations) were calculated. Full optimisation was performed for all found local minima. The dehydroamino acids are achiral and each conformation $(\varphi, \psi)$ has related pair $(-\varphi,-\psi)$ with the same energy but with opposite torsion angles so that only half of the map is needed to be calculated. Calculations were performed for molecules with the trans-amide bond. For the compounds (3-5), the minima were calculated on the basis of the map for $\mathbf{2}$ as well as the minima of corresponding oxazole-amino acids (Siodłak et al. 2014a). The conformers' names are based on the Scarsdale nomenclature (Scarsdale et al. 1983; Hudáky et al. 2004).

Based on our previous studies (Siodłak et al. 2014b) the meta-hybrid M06-2X/6-311++G(d,p) (Zhao and Truhlar 2008) level of theory was chosen. To estimate the solvation effects on the conformations, calculations were also conducted using a self-consistent reaction field (SCRF) with the SMD method (Kang et al. 2011; Kang and Park 2014). The Gaussian 16 package was used (Frisch et al. 2016). The NBO analysis was performed using the same method and basis set as mentioned before (Weinhold and Landis 2001). Frequency analyses were carried out to verify the nature of<smiles>CC(=O)NC(C)c1nc(C)cs1</smiles>

(1)<smiles>C=C(NC(C)=O)c1nc(C)cs1</smiles>

Ac- $\triangle$ Ala-Tzl(4-Me)

(2)

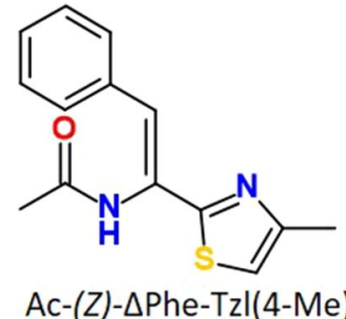

(4)

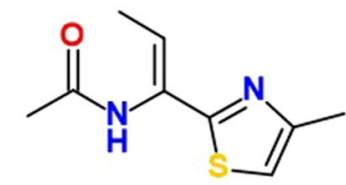

Ac-(Z)- $\triangle \mathrm{Abu}-\mathrm{Tzl}(4-\mathrm{Me})$

(3)

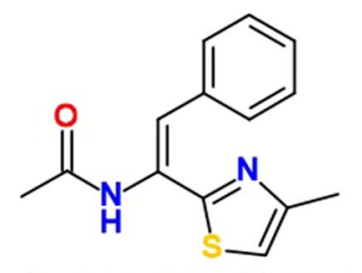

(5)
Fig. 2 Schematic formula for the studied compounds (1-5) the minimum state of all stationary points and to calculate the zero-point vibrational energies (ZPVEs). The expected population $(p)$ of the conformers at a temperature of $300 \mathrm{~K}$ (where $\mathrm{RT}=0.595 \mathrm{kcal} / \mathrm{mol}$ ) was calculated (Hudáky and Perczel 2008; Hruby et al. 1997). Interaction energy in gas phase and water as a solvent between water molecules and oxazole/thiazole was investigated using molecular dynamic and density functional theory. The initial geometry of oxazole and thiazole molecules was created in GaussView6 program (Dennington et al. 2016) and their structures were optimised. Molecular dynamic simulation, $10 \mathrm{~ns}$ at $300 \mathrm{~K}$, in explicit water was set up for both rings. Periodic boundary was used. The rings were solvated in a periodic rectangular box filled with water (TIP3PBOX 12) using TLeap. The structures were equilibrated with the Amber14 package (Case et al. 2014) using supplied general amber force field (GAFF) for the rings and "ff14SB" force filed for water. Atomic charges were obtained from the R.E.D server (Bayly et al. 1993; Vanquelef et al. 2011; Dupradeau et al. 2010). After a sequence of restrained minimisations and heating, $100 \mathrm{ps}$ equilibration dynamics was performed at $300 \mathrm{~K}$ without any restraints. The 200 initial structures obtained by taking snapshots from the MD trajectory at 5 ps intervals with the makea and xshell programs. The first solvation shell was considered in the distance of $2.5 \AA$. The DFT optimisation for obtained complexes was performed in gas phase and implicit water (SCRF/SMD) (Kang et al. 2011; Kang and Park 2014) with the M06-2X/6-311++G(d,p) level of theory. All optimised complexes without imaginary frequencies were analysed further.

\section{Results and discussion}

\section{Thiazole-alanine}

Figure 3 presents the potential energy surfaces of Ac-L-Ala-Tzl(4-Me) (1) in three various environments; gas phase for isolated molecule, chloroform mimicking weakly polar inside of protein, and water as a natural solvent. Regardless of the simulated environment, five energy minima were found: $\beta 2, \beta, \alpha \mathrm{L}, \alpha \mathrm{D}, \alpha \mathrm{R}$ (Table 1 ).

In the gas phase, the global minimum is occupied by the semi-extended conformation $\beta 2\left(\varphi, \psi=-160^{\circ},-6^{\circ}\right)$. Its population is quite high, around $79 \%$. The stability of this conformation can be explained by the presence of intramolecular hydrogen bonds; $\mathrm{N}-\mathrm{H} \cdots \mathrm{N}_{\mathrm{TZL}}$ formed between the hydrogen atom of amide group and the nitrogen atom of thiazole ring as well as $\mathrm{C} \alpha-\mathrm{H} \cdots \mathrm{O}$ hydrogen bond created by the hydrogen atom of $\alpha$ carbon atom and the oxygen atom of amide group. The parameters of intramolecular hydrogen bonds can be found in Table S1 in Supporting Information. Next in energy order are the conformation $\beta$ 


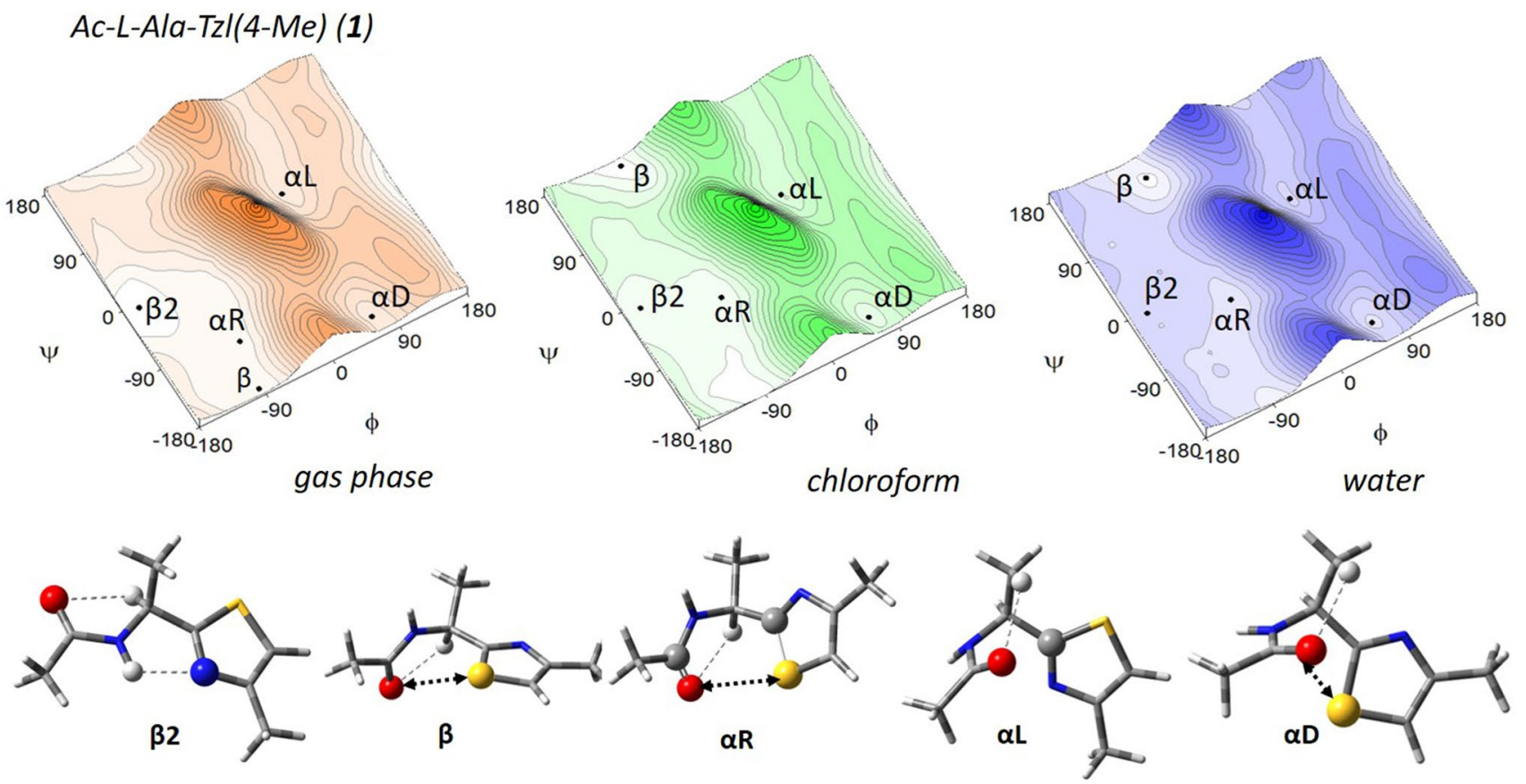

Fig. 3 The potential energy surfaces $E=f(\varphi, \psi)$ for Ac-L-Ala-Tzl $(4-$ Me) (1) calculated by M06-2X/6-311++G(d,p) method in various environment. Energy contours are plotted every $1 \mathrm{kcal} / \mathrm{mol}$. Con-

Table 1 Selected torsion angles $\left(^{\circ}\right)$ of local minima for Ac--L-Ala$\mathrm{Tzl}(4-\mathrm{Me})(\mathbf{1})$, their relative energies $(\Delta \mathrm{E})$ in $\mathrm{kcal} / \mathrm{mol}$ and population $(p)$, optimised by M06-2X/6-311++G(d,p) method

\begin{tabular}{lrrrr}
\hline Ac-L-Ala-Tzl(4-Me) $(1)$ & & & \\
\hline Conformer & \multicolumn{1}{c}{$\varphi$} & $\psi$ & $\Delta \mathrm{E}$ & $p[\%]$ \\
\hline Gas phase & & & & \\
$\beta 2$ & -160.4 & -5.7 & 0.00 & 78.7 \\
$\beta$ & -95.2 & -171.9 & 1.20 & 10.5 \\
$\alpha \mathrm{R}$ & -82.8 & -106.0 & 1.22 & 10.1 \\
$\alpha \mathrm{D}$ & 64.7 & -158.4 & 3.13 & 0.4 \\
$\alpha \mathrm{L}$ & 56.4 & 36.7 & 3.38 & 0.3 \\
Chloroform & & & & \\
$\beta$ & -82.3 & 170.7 & 0.00 & 57.6 \\
$\beta 2$ & -159.2 & -8.13 & 0.48 & 25.9 \\
$\alpha \mathrm{R}$ & -70.3 & -42.6 & 0.86 & 13.6 \\
$\alpha \mathrm{D}$ & 64.1 & -154.1 & 1.98 & 2.1 \\
$\alpha \mathrm{L}$ & 56.8 & 37.9 & 2.51 & 0.9 \\
Water & & & & \\
$\beta$ & -67.3 & 153.3 & 0.00 & 80.8 \\
$\alpha \mathrm{R}$ & -65.3 & -38.9 & 1.10 & 12.8 \\
$\alpha \mathrm{D}$ & 60.0 & -147.2 & 2.00 & 2.8 \\
$\beta 2$ & -159.1 & -8.6 & 2.10 & 2.4 \\
$\alpha \mathrm{L}$ & 58.2 & 39.3 & 2.51 & 1.2 \\
\hline & & & &
\end{tabular}

formations optimised in chloroform with most important stabilising internal forces; hydrogen bonds $(\cdots)$ and electrostatic interactions $(<\cdots)$

$\left(\varphi, \psi=-95^{\circ},-172^{\circ}\right)$ and the right-handed helical $\alpha \mathrm{R}(\varphi$, $\left.\psi \sim 83^{\circ}, 106^{\circ}\right)$. They are expected to be adopted by $10 \%$ of the population each. Both conformations are stabilised by weaker $\mathrm{C} \alpha-\mathrm{H} \cdots \mathrm{O}$ hydrogen bonds and electrostatic attractive interactions between the amide oxygen atom (NBO charge -0.66$)$ and thiazole sulfur atom (NBO charge +0.40$)$ (Tables S1 and S2). The remaining conformations $\alpha \mathrm{D}(\varphi$, $\left.\psi=65^{\circ},-158^{\circ}\right)$ and $\alpha \mathrm{L}\left(\varphi, \psi=56^{\circ}, 37^{\circ}\right)$ have much higher energies $(\Delta E>3 \mathrm{kcal} / \mathrm{mol})$ and their populations are estimated on less than $0.5 \%$. Their presence on the maps can be explained mainly by electrostatic interactions.

The increase of polarity of environment results in a change of energy order of conformations so that the structure $\beta$ becomes the lowest one. Moreover, a decrease in energy gaps between the conformations is observed. This is because the conformations higher in energy for isolated molecule, $\alpha \mathrm{D}$, and $\alpha \mathrm{L}$, gain stability from interactions with polar solvent; whereas, the conformations $\beta 2, \beta$, and $\alpha \mathrm{R}$ still have functional group involved in internal interactions.

The potential energy surface is relatively flat in the regions surrounding three the lowest in energy conformations, $\beta 2, \beta$, and $\alpha \mathrm{R}$. This indicates that considerable conformational changes can be made at a relatively low energy cost. In fact, conformers $\beta$ and $\alpha \mathrm{R}$ undergo significant geometrical changes, up to $30^{\circ}$ and even $70^{\circ}$, respectively, in case of value of torsion angle $\psi$ when the environment is changed from gas phase to water. In contrast, the geometry of conformations $\beta 2, \alpha \mathrm{D}$, and $\alpha \mathrm{L}$ seems to be independent 
of polarity of studied environments. The rigidity of conformation $\beta 2$ seems to result from the presence of the internal $\mathrm{N}-\mathrm{H} \cdots \mathrm{N}_{\text {TZL }}$ hydrogen bond. It is still maintained in a more polar environment; however, the amide $\mathrm{N}-\mathrm{H}$ group is not involved in an intermolecular interaction, and thus its relative energy increases. The rigidity of conformations $\alpha \mathrm{D}$ and $\alpha \mathrm{L}$ does not result from any stable internal stabilising forces, but rather from steric repulsion. This indicates that with the increase of polarity of environment, stability is gained rather from intermolecular than intramolecular interactions.

\section{Thiazole-dehydroalanine}

The conformational maps for Ac- $\Delta$ Ala-Tzl(4-Me) (2) show that for this residue four pairs of potential energy minima can be possible (Fig. 4). Due to the lack of chirality of the carbon atom $\alpha$ the maps are symmetric. Considering the left side of maps four minima can be found, $\beta 2, C 5, \beta$, and $\alpha$, but their analogues with the same energy but opposite sign of torsion angles are present on the right side (Table 2). The number and types of conformations do not change, regardless of the simulated environment.

Both in the gas phase and the studied solvents, the global minimum corresponds to the conformation $\beta 2(\varphi, \psi$ $\approx 180^{\circ}, 0^{\circ}$, which is stabilszed mainly by the intramolecular $\mathrm{N}-\mathrm{H} \cdots \mathrm{N}_{\mathrm{TZL}}$ hydrogen bond, created between the amide group and thiazole nitrogen atom. There is also the
Table 2 Selected torsion angles $\left({ }^{\circ}\right)$ of local minima for Ac $-\Delta$ Ala$\mathrm{Tzl}(4-\mathrm{Me})(2)$, their relative energies $(\Delta \mathrm{E})$ in $\mathrm{kcal} / \mathrm{mol}$, and population $(p)$, optimised by M06-2X/6-311++G(d,p) method

\begin{tabular}{lrrrr}
\hline Ac- $\Delta$ Ala-Tzl(4-Me) (2) & & & \\
\hline Conformer & \multicolumn{1}{l}{$\varphi$} & $\psi$ & $\Delta \mathrm{E}$ & $p[\%]$ \\
\hline Gas phase & & & & \\
$\beta 2$ & -180.0 & 0.0 & 0.00 & 99.94 \\
C5 & -161.3 & -156.4 & 4.56 & 0.05 \\
$\beta$ & -62.9 & 164.0 & 5.80 & 0.01 \\
$\alpha$ & 47.1 & 32.7 & 6.08 & 0.00 \\
Chloroform & & & & \\
$\beta 2$ & -180.0 & 0.0 & 0.00 & 98.87 \\
C5 & -150.5 & -156.0 & 3.09 & 0.55 \\
$\beta$ & -61.1 & 159.1 & 3.30 & 0.39 \\
$\alpha$ & 49.8 & 32.4 & 3.72 & 0.19 \\
Water & & & & \\
$\beta 2$ & -180.0 & 0.0 & 0.00 & 68.56 \\
$\beta$ & -58.3 & 153.8 & 0.86 & 16.20 \\
$\alpha$ & 52.0 & 33.7 & 1.18 & 9.48 \\
C5 & -137.9 & -153.5 & 1.47 & 5.77 \\
\hline
\end{tabular}

$\mathrm{C} \beta-\mathrm{H} \cdots \mathrm{O}$ interaction. The values of torsion angles $\varphi$ and $\psi$ indicate the flatness of structure, due to the presence of $\alpha, \beta$ double bond neighbouring with the amide group and thiazole ring so that the conformation $\beta 2$ gains stability from the

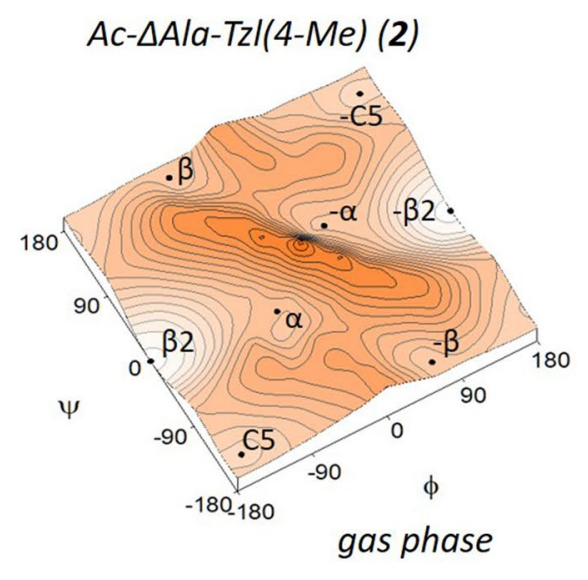

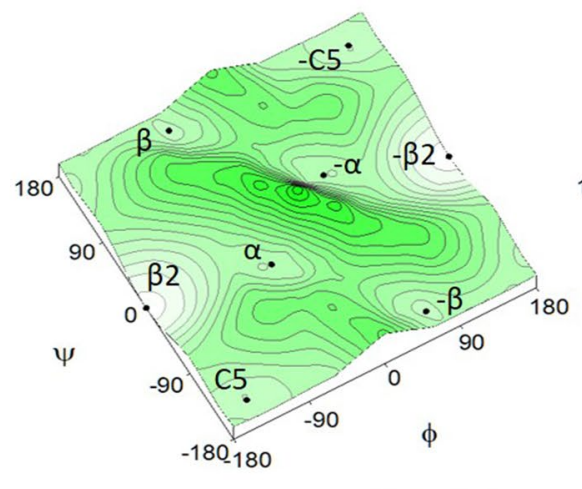

chloroform

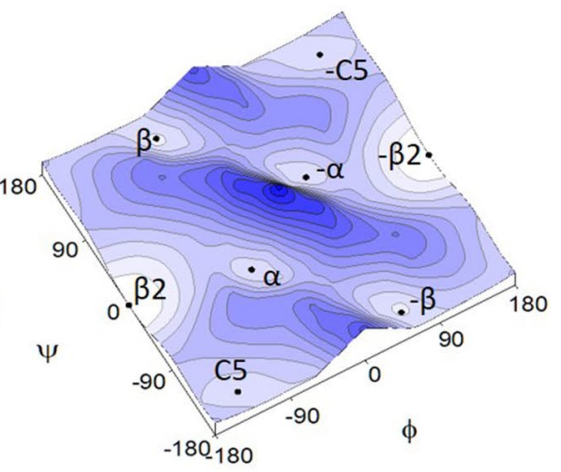

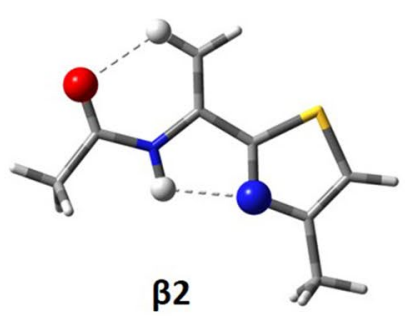

$\beta 2$

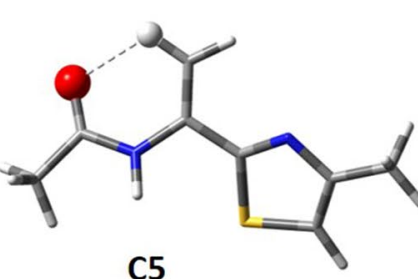

C5

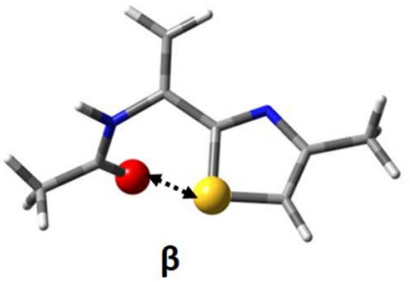

water

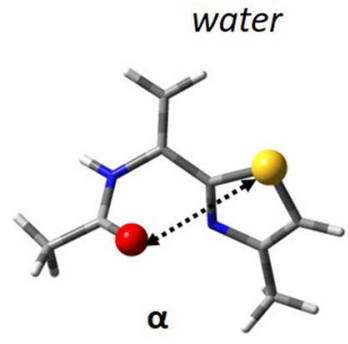

Fig. 4 The potential energy surfaces $E=f(\varphi, \psi)$ for Ac- $\Delta$ Ala-Tzl(4Me) (2) calculated by M06-2X/6-311++G(d,p) method in various environment. Energy contours are plotted every $1 \mathrm{kcal} / \mathrm{mol}$. Confor- mations optimised in chloroform with most important electrostatic interactions $(\cdots)$ ) and hydrogen bond $(\cdots)$ 
cross-conjugate $\pi$-electron system. The remaining conformation $\mathrm{C} 5\left(\varphi, \psi \approx-161^{\circ},-156^{\circ}\right), \beta\left(\varphi, \psi \approx-63^{\circ},-164^{\circ}\right)$, and $\alpha\left(\varphi, \psi \approx 47^{\circ}, 33^{\circ}\right)$ are stabilised only by the $\mathrm{C} \beta-\mathrm{H} \cdots \mathrm{O}$ (C5), and electrostatic interactions ( $\beta$ and $\alpha$ ). The values of torsion angles indicate that for these conformations the $\pi$-electron conjugation is insignificant. This explains their high relative energy.

The results of calculations show that also in the polar environment the conformer $\beta 2$ is also the most stable. Its population is very high in gas phase and chloroform, around $99 \%$, and still prevails in water (69\%). The geometry does not change, which indicates stability gained from intramolecular forces. The relative energies of the remaining conformers, C5, $\beta$, and $\alpha$, are still high in a weakly polar chloroform, but considerably decrease in water. On the other hand, the geometry of conformations is generally maintained, except for the conformer $\mathrm{C} 5$, where the angle $\varphi$ changes by about $23^{\circ}$ when switching from gas to water. The presented results indicate that the environment does not influence the geometry of conformations of thiazole-dehydroalanine residue, but it does the relative energy through the interactions with the solvent, which stabilised all conformers.

The conformation C5 is not available for the saturated analogue (1). Comparing the shape of conformational maps for molecules (1) and (2), it seems that minima are better defined for (2). The presence of double bond in the side chain gives the ability to create additional stabilising force, the $\pi$-electron conjugation, which considerably increases the stability of flat conformers: $\beta 2$ and $\mathrm{C} 5$. This causes, that the minima found for Ac- $\Delta \mathrm{Ala}-\mathrm{Tzl}(4-\mathrm{Me})$ are more stable and have less conformational freedom than those found for Ac-L-Ala-Tzl(4-Me). However, in water, the energy differences between conformations are blurring.

\section{Thiazole-(Z)-dehydrobutyrine}

Figure 5 and Table 3 present the four conformers found for Ac- $(\mathrm{Z})-\Delta \mathrm{Abu}-\mathrm{Tzl}(4-\mathrm{Me})(3): \beta 2\left(\varphi, \psi \approx-126^{\circ},-4^{\circ}\right)$, C5 $\left(\varphi, \psi \approx-123^{\circ}, 164^{\circ}\right), \beta\left(\varphi, \psi \approx-69^{\circ}, 169^{\circ}\right)$, and $\alpha\left(\varphi, \psi \approx 56^{\circ}, 22^{\circ}\right)$. The number and type of conformations are the same as in the case of analogue (2). Also, the
Table 3 Selected torsion angles $\left(^{\circ}\right)$ of local minima for Ac-(Z) $\Delta \mathrm{Abu}-\mathrm{Tzl}(4-\mathrm{Me})(3)$, their relative energies $(\Delta \mathrm{E})$ in $\mathrm{kcal} / \mathrm{mol}$ and population $(p)$, optimised by M06-2X/6-311++G(d,p) method

\begin{tabular}{|c|c|c|c|c|}
\hline \multicolumn{5}{|c|}{$\mathrm{Ac}-(\mathrm{Z})-\Delta \mathrm{Abu}-\mathrm{Tzl}(4-\mathrm{Me})(3)$} \\
\hline Conformer & $\varphi$ & $\psi$ & $\Delta \mathrm{E}$ & $p[\%]$ \\
\hline \multicolumn{5}{|l|}{ Gas Phase } \\
\hline$\beta 2$ & -125.8 & -3.5 & 0.00 & 90.3 \\
\hline $\mathrm{C} 5$ & -122.8 & -164.1 & 1.37 & 9.0 \\
\hline$\beta$ & -69.2 & 169.4 & 3.12 & 0.5 \\
\hline$\alpha$ & 56.3 & 22.2 & 3.56 & 0.2 \\
\hline \multicolumn{5}{|l|}{ Chloroform } \\
\hline$\beta 2$ & -124.5 & 2.8 & 0.00 & 55.4 \\
\hline C5 & 122.3 & 161.3 & 0.34 & 31.2 \\
\hline$\beta$ & -66.4 & 163.5 & 1.07 & 9.3 \\
\hline$\alpha$ & 52.3 & 29.4 & 1.54 & 4.2 \\
\hline \multicolumn{5}{|l|}{ Water } \\
\hline $\mathrm{C} 5$ & 118.9 & 160.2 & 0.00 & 35.2 \\
\hline$\beta$ & -62.5 & 156.6 & 0.10 & 29.7 \\
\hline$\beta 2$ & -122.3 & 16.4 & 0.27 & 22.5 \\
\hline$\alpha$ & 54.7 & 32.5 & 0.61 & 12.6 \\
\hline
\end{tabular}

energy order of conformations is the same both for isolated molecule and in a weakly polar environment. However, difference occurs in case of the conformers $\beta 2$ and $\mathrm{C} 5$, where the value of torsion angle $\varphi$ is about $-120^{\circ}$ due to the steric hindrance imposed by the methyl group in position $Z$ of the side chain. This causes that $\mathrm{C} \beta-\mathrm{H} \cdots \mathrm{O}$ H-bond is absent and $\mathrm{N}-\mathrm{H} \cdots \mathrm{N}$ hydrogen bond and $\pi$-electron conjugation are distorted. In consequence, the conformation $\beta 2$ is less stable what diminishes the energy gap between the conformations so that the conformation $\beta 2$ is less dominant. In gas phase its population reaches $90 \%$, but in chloroform it diminishes to 55\%, and in water further decreases to $22 \%$. In the water environment, the global minimum is changed, the lowest in energy is the conformation C5. The population of the first three conformations occurs with a similar probability of around $30 \%$. It should be also noticed that the energy differences are within the

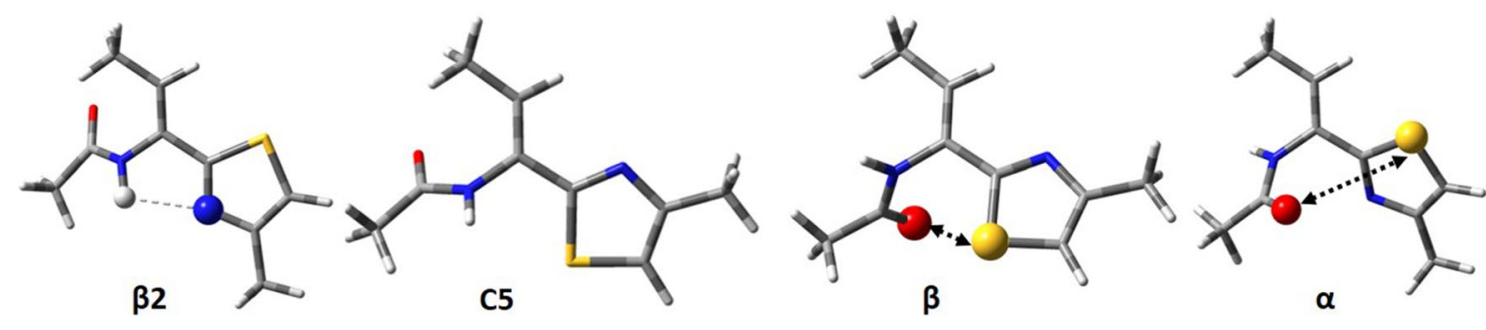

Fig. 5 Conformers for Ac-(Z)- $\Delta$ Abu-Tzl(4-Me) (3) calculated by M06-2X/6-311++G(d,p) method in chloroform with most important electrostatic interactions $(<\cdots)$ and hydrogen bond $(\cdots)$ 
error bar of method and do not exceed $1 \mathrm{kcal} / \mathrm{mol}$. Therefore, in this case, none of the conformation is favoured.

\section{Thiazole-dehydrophenylalanine}

Both geometric isomers of thiazole-dehydrophenylalanine can adopt, regardless of the environment, four different conformations: $\beta 2, \beta, \mathrm{C} 5$, and $\alpha$ (Fig. 6, Table 4). The geometry of conformations for Ac-(Z)- $\Delta$ Phe-Tzl(4-Me) (4): $\beta 2(\varphi, \psi$ $\left.\approx-129^{\circ}, 0^{\circ}\right), \beta\left(\varphi, \psi \approx-69^{\circ}, 167^{\circ}\right), \alpha\left(\varphi, \psi \approx 48^{\circ}, 32^{\circ}\right)$, and C5 $\left(\varphi, \psi \approx-123^{\circ}, 165^{\circ}\right)$ is very similar to the analogue (3). However, the energy difference $(\Delta \mathrm{E})$ between the conformations is considerably smaller. Although for the isolated molecule the conformation $\beta 2$ prevails, in a polar environment a tendency towards the conformation $\beta$ is observed. Nevertheless, $\Delta \mathrm{E}$ is below $1 \mathrm{kcal} / \mathrm{mol}$, so the conformational equilibrium is predicted. It seems that the phenyl ring imposes greater steric hindrance than the methyl group in the case of (3).

Analysis of conformations of the isomer $E$, Ac- $(E)-\Delta$ Phe-Tzl(4-Me) $(5): \beta 2\left(\varphi, \psi \approx-179^{\circ}, 0^{\circ}\right), \alpha$ $\left(\varphi, \psi \approx 41^{\circ}, 49^{\circ}\right), \mathrm{C} 5\left(\varphi, \psi \approx-161^{\circ},-131^{\circ}\right)$, and $\beta(\varphi, \psi$ $\approx-57^{\circ}, 146^{\circ}$ ), shows differences in geometry and relative energy between the isomers. The conformation $\beta 2$ is flat and resembles that for the thiazole-dehydroalanine (2). The parameters of $\mathrm{N}-\mathrm{H} \cdots \mathrm{N}$ hydrogen bond are better than for the analogue $Z$ (4) (Table S1). Additionally, an interaction between the aromatic ring and sulfur atom can be considered. The phenyl group in position $E$ does not impose steric hindrance on the $\mathrm{N}$-terminal amide group so that the value of torsion angle $\varphi$ is close to $180^{\circ}$ and the $\pi$-electron conjugation between $\mathrm{N}$-terminal amide group and $\mathrm{C} \alpha=\mathrm{C} \beta$ double bond should be present. In results, the energy of the conformation $\beta 2$ for isolated molecules and even for the weakly polar environment has considerably low energy, so that the conformation $\beta 2$ gathers almost the whole population of molecules. In a more polar water environment, sterically more open conformations $\alpha$ and $\beta$ prevail, due to better interaction with solvent, and the position of substituent in the side chain seems does not influence their geometry. In contrast, in the conformation $\mathrm{C} 5$ the phenyl ring imposes a steric hindrance, thus the value of torsion angle $\psi$ is the lowest amongst the studied residues.

\section{Solid-state conformations from CSD}

The solid-state crystal structure conformations of thiazole-amino acid residues, as well as oxazole-amino acid residues, were retrieved from the Cambridge Structural Database (Groom et al. 2016) and presented on the potential energy surface calculated for L-Ala-Tzl (1) (Fig. 7).

The amino acid residues found adjacent to the triazole ring are mainly valine- (Doi et al. 2001; McDonald et al. 1992; Todorova et al. 1995; Haberhauer et al. 2008; Asano et al. 2001, 2002a, 2002b, 2003, 2005; Asano and Doi 2004; Ishida et al. 1992; In et al. 1994; You and Kelly 2005; Bertram et al. 2003), phenylalanine- (Mali et al. 2012; Pettit et al. 1994, 2004), glycine- (Li et al. 2013;
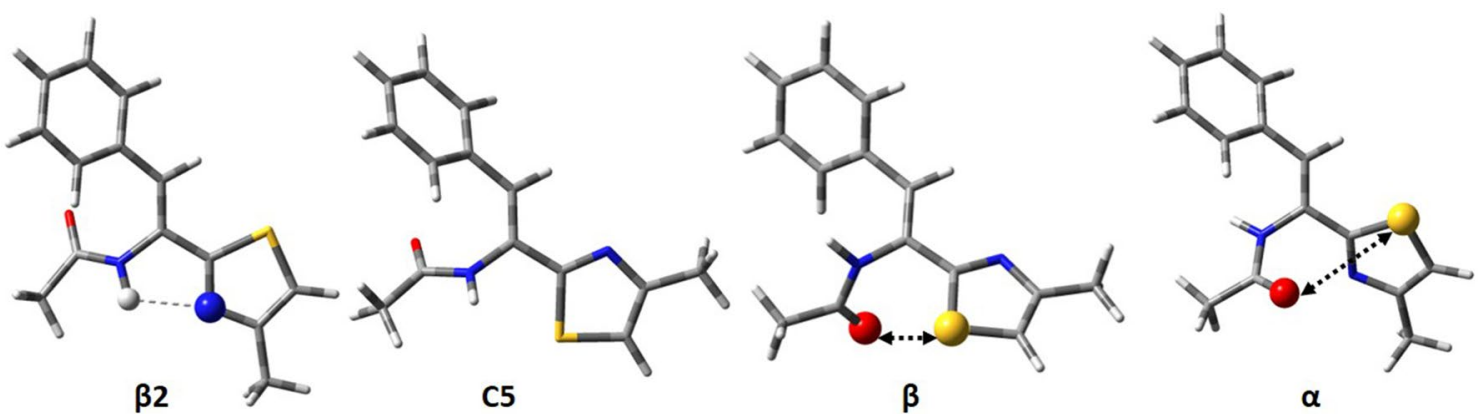

$\alpha$
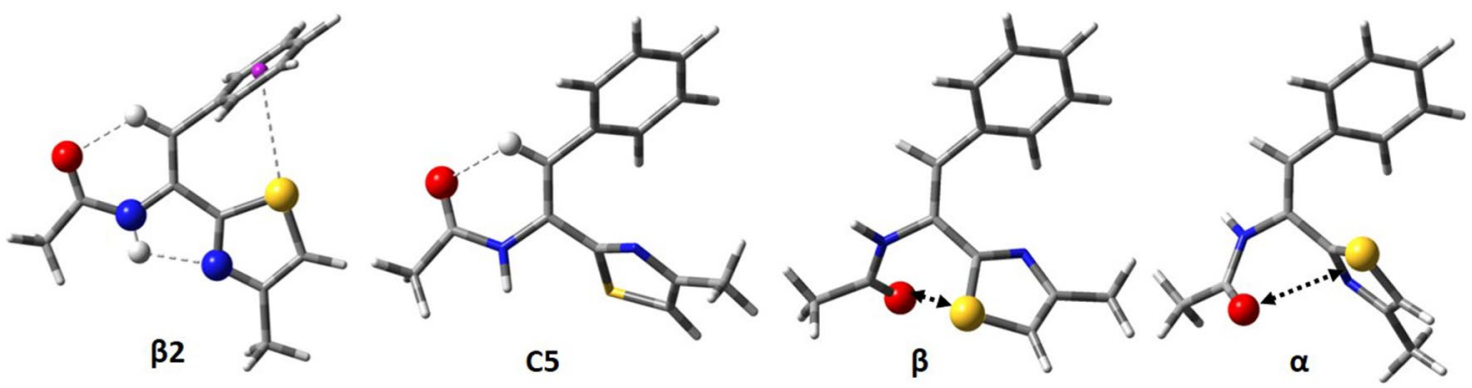

Fig. 6 Conformers for Ac-(Z)- $\Delta$ Phe-Tzl(4-Me) (4) and Ac-(E)- - Phe-Tzl(4-Me) (5) calculated by M06-2X/6-311++G(d,p) method in chloroform with most important electrostatic interactions $(\longrightarrow \cdots)$ ) and hydrogen bond $(\cdots)$ 
Table 4 Selected torsion angles $\left({ }^{\circ}\right)$ of local minima for Ac-(Z)- $\Delta$ Phe-Tzl(4-Me) (4) and $\mathrm{Ac}-(E)-\Delta \mathrm{Phe}-\mathrm{Tzl}(4-\mathrm{Me})$ $(5)$, their relative energies $(\Delta \mathrm{E})$ in $\mathrm{kcal} / \mathrm{mol}$ and population ( $p)$, optimised by M06-2X/6$311++\mathrm{G}(\mathrm{d}, \mathrm{p})$ method

\begin{tabular}{|c|c|c|c|c|c|c|}
\hline Conformer & $\varphi$ & $\psi$ & $\tau$ & $\chi$ & $\Delta \mathrm{E}$ & $p[\%]$ \\
\hline \multicolumn{7}{|c|}{ Ac- $(\mathrm{Z})-\Delta \mathrm{Phe}-\mathrm{Tzl}(4-\mathrm{Me})(4)$} \\
\hline \multicolumn{7}{|l|}{ Gas phase } \\
\hline$\beta 2$ & -129.2 & 0.1 & 8.7 & 23.8 & 0.00 & 66.1 \\
\hline$\beta$ & -68.6 & 167.3 & -7.2 & -41.7 & 0.62 & 23.2 \\
\hline$\alpha$ & 48.0 & 31.5 & 7.2 & 38.5 & 1.42 & 6.0 \\
\hline $\mathrm{C} 5$ & -123.3 & -165.4 & 6.8 & 33.1 & 1.58 & 4.6 \\
\hline \multicolumn{7}{|c|}{ Chloroform } \\
\hline$\beta$ & -63.6 & 161.6 & -6.6 & -34.6 & 0.00 & 42.8 \\
\hline$\beta 2$ & -127.4 & 5.9 & 9.0 & 21.4 & 0.34 & 24.1 \\
\hline$\alpha$ & 50.8 & 30.4 & 7.1 & 35.1 & 0.55 & 17.1 \\
\hline $\mathrm{C} 5$ & -121.7 & -164.7 & 6.5 & 32.7 & 0.59 & 16.0 \\
\hline \multicolumn{7}{|l|}{ Water } \\
\hline$\beta$ & -64.5 & 157.8 & -6.4 & -30.5 & 0.00 & 47.5 \\
\hline $\mathrm{C} 5$ & -122.2 & -161.4 & 5.9 & 26.6 & 0.40 & 24.2 \\
\hline$\alpha$ & 57.2 & 29.4 & 7.0 & 33.2 & 0.71 & 14.4 \\
\hline$\beta 2$ & -127.0 & 16.9 & 8.3 & 20.3 & 0.73 & 13.8 \\
\hline \multicolumn{7}{|c|}{$\mathrm{Ac}-(\mathrm{E})-\Delta \mathrm{Phe}-\mathrm{Tzl}(4-\mathrm{Me})(5)$} \\
\hline \multicolumn{7}{|l|}{ Gas phase } \\
\hline$\beta 2$ & -179.3 & 0.1 & -179.9 & -91.2 & 0.00 & 99.9 \\
\hline$\alpha$ & 40.6 & 48.7 & -168.2 & 38.4 & 4.66 & 0.0 \\
\hline C5 & -161.2 & -130.7 & -173.5 & 40.1 & 4.73 & 0.0 \\
\hline$\beta$ & -56.6 & 146.1 & 169.9 & 47.4 & 7.00 & 0.0 \\
\hline \multicolumn{7}{|c|}{ Chloroform } \\
\hline$\beta 2$ & -179.8 & -1.3 & 179.5 & 93.9 & 0.00 & 93.7 \\
\hline$\alpha$ & 41.3 & 48.9 & -168.2 & 38.8 & 1.86 & 4.1 \\
\hline $\mathrm{C} 5$ & -146.5 & -134.7 & -171.7 & 39.3 & 2.26 & 2.1 \\
\hline$\beta$ & -54.3 & 141.5 & 169.5 & 49.9 & 4.18 & 0.1 \\
\hline \multicolumn{7}{|l|}{ Water } \\
\hline$\alpha$ & 44.9 & 46.7 & -168.9 & 40.1 & 0.00 & 39.9 \\
\hline$\beta$ & -48.5 & 134.3 & 168.9 & -35.8 & 0.10 & 33.8 \\
\hline$\beta 2$ & -149.7 & 48.2 & -172.7 & 39.9 & 0.48 & 17.8 \\
\hline $\mathrm{C} 5$ & -139.5 & -131.4 & -171.3 & 36.8 & 0.93 & 8.4 \\
\hline
\end{tabular}

Bernhardt et al. 2002; Seiser et al. 2008; Kaiser et al. 2000; Stezowski et al. 1987) and alanine- (Schmitz et al. 1989; Vollbrecht et al. 2002; Zhou et al. 2012; Breydo et al. 2002) and other (Fletton et al. 1983; Nicolaou et al. 2003; Merino et al. 1998; Dondoni et al. 1995; Marsh 1997). Amongst 139 thiazole-amino acid residues, 81\% can be found in the region of the conformation $\beta 2$, and $10 \%$ adopt the conformation $\beta$. There are also structures, which represent the conformations $\alpha \mathrm{R}, \alpha \mathrm{L}$, and $\alpha \mathrm{D}$, although their population is considerably smaller. It should be noted that the residues occur in macrocyclic peptides, thus the geometrical strains in those macrocycles can have some impact on the adopted conformation. Nevertheless, it can be confirmed that the calculation relatively good predicts the conformations adopted by the thiazole-amino acid residues and also show that the side chain is not the leading feature that causes conformational propensity.

\section{Comparison to oxazole-amino acid}

In our previous studies, we have analysed the conformational properties of oxazole-amino acid for analogous residues (Siodłak et al. 2014a; Staś et al. 2016b). Comparison of the relative energy of oxazole- and thiazole-amino acid conformers with the same side chain (Fig. 3S) shows similar conformational profiles; the type of conformations and energy order. Nevertheless, some differences can be seen. Thiazole-alanine (Ala-Tzl), and by analogy, other saturated side chain residues, have more available low-energy 


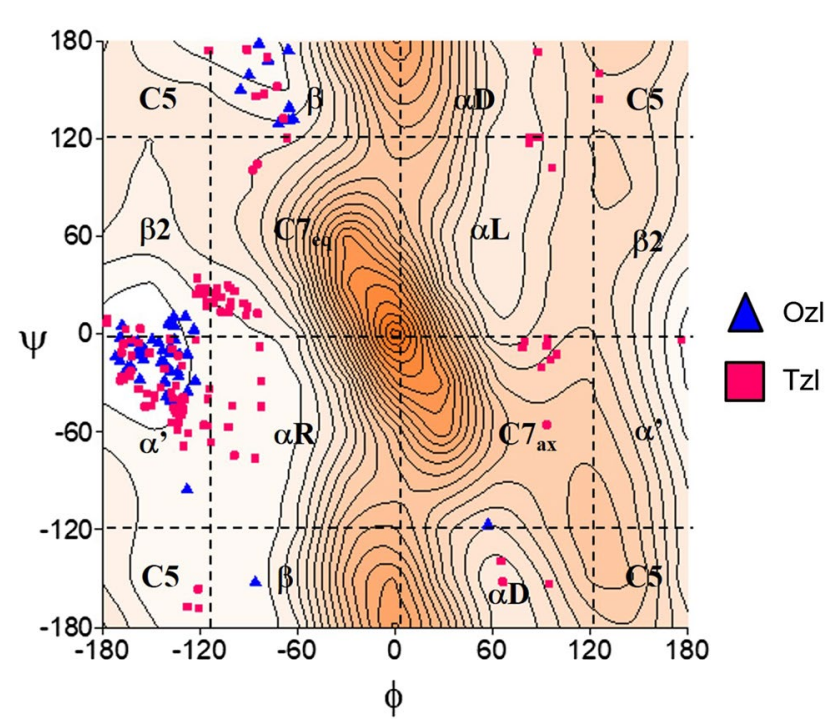

Fig. 7 The potential energy surface, $\mathrm{E}=\mathrm{f}(\varphi, \psi)$, for Ac-L-Ala-Tzl $(4-$ Me) calculated by M06-2X/6-311++G(d,p) method in vacuo with solid-state crystal structure conformations of thiazole-amino acid residues (pink square) and oxazole-amino acid residues (blue triangular) retrieved from the Cambridge Structural Database. Energy contours are plotted every $1 \mathrm{kcal} / \mathrm{mol}$

conformations ( $\beta 2$ and $\beta$ ) than oxazole-alanine (Ala-Ozl), at least in a low polar environment. In contrast, thiazole-dehydroalanine ( $\Delta$ Ala-Tzl) shows greater conformational restriction than oxazole analogue, and it seems that it has a much greater tendency to adopt solely the conformation $\beta 2$. A similar effect can be seen for thiazole-dehydrophenylalanine ( $\Delta$ Phe-Tzl), both isomers $Z$ and $E$, for isolated molecules. Thiazole-dehydrobutyrine $(Z-\Delta \mathrm{Abu}-\mathrm{Tzl})$ seems to have more conformational freedom, regardless of the mimicking environment.

\section{Interaction between a water molecule and thiazole / oxazole ring}

In order to gain further information about the role of thiazole ring in the creation of intra- and intermolecular interactions, crucial for existence and energy order of thiazole-amino acid conformations, the interaction of water molecule with thiazole ring was simulated by MD. According to the simulations, in the first solvation shell of thiazole ring (in the distance of $2.5 \AA$ ) are present from none to three water molecules, in case of oxazole ring it is from none to four. Percentage analysis for 200 snapshots are shown in the Table S3. The interaction of thiazole ring with one water molecule it is always from the nitrogen atom side. Examples of complexes optimised by DFT in vacuo and water are in Fig. 8. The estimated strength of hydrogen bond between one water molecule and thiazole ring is about $5 \mathrm{kcal} / \mathrm{mol}$ (Tzl-N1 and Tzl-N2) for isolated complexes (Fig. 8). If the water environment is considered, the energy was estimated at $2 \mathrm{kcal} / \mathrm{mol}$. The analogous calculations for the oxazole ring still indicate some energy profit (Figure S2). The simulation shows that despite structural similarity, thiazole ring moiety will have a different influence on conformational properties than oxazole analogue. It also explains why a nitrogen atom in the thiazole is a preferred site for metal chelation (Le et al. 2010). The sulfur atom contributes with its lone pair to an electronic sextet; whereas, the nitrogen atom has free lone pair ready for interactions with other atoms. In the $\mathrm{C}-\mathrm{S}$ bond is created $\sigma$-hole, due to sulfur low-lying $\sigma^{*}$ orbitals. It causes that this atom has positive electrostatic potential in the thiazole ring.

\section{Conclusions}

Conformational analysis of selected thiazole-amino acid residues, most commonly found in nature, indicates that the combination of two structural motifs, amino acid side chain and thiazole ring gives unique properties of such residues.

The characteristic feature is the low-energy conformation $\beta 2$, unusual for standard amino acid residues. This conformation is stabilised by an intramolecular hydrogen bond $\mathrm{N}-\mathrm{H} \cdots \mathrm{N}_{\text {TZL }}$, between the $\mathrm{N}$-terminal $\mathrm{N}-\mathrm{H}$ amide group and the nitrogen atom of the thiazole ring. Analysis of thiazole-alanine (1) supported by the conformations of the solid-state crystal structures retrieved from the Cambridge Structural Database shows that this unique semi-extended conformation $\beta 2\left(\phi, \psi \sim-160^{\circ}, 8^{\circ}\right)$ is characteristic also for other thiazole-amino acid residues. The population of conformation $\beta 2$ is considerable at least in a low polar environment.

The thiazole-dehydroamino acids (2-5) have different conformational profiles due to the presence of $\mathrm{C} \alpha=\mathrm{C} \beta$ double bond and the lack of chirality. Nevertheless, the conformation $\beta 2$ seems to be even more stable due to $\pi$-electron cross-conjugation. It is heavily populated for thiazole-dehydrobutyrine $(2)\left(\phi, \psi \sim-125^{\circ}, 5^{\circ}\right)$ or even predominate for naturally occurring thiazole-dehydroalanine (1) $(\phi$, $\psi \sim-180^{\circ}, 0^{\circ}$ ), regardless of the studied environment. Analysis of the $Z$ and $E$ geometric isomers of thiazole-dehydrophenylalanine (4 and $\mathbf{5}$ ) indicates that the position of side chain is important, pointing to a potential conformational switch.

The properties of thiazole ring and the presence of sulfur atom are also far-reaching. The positive electrostatic potential of the sulfur atom creates possible intramolecular electrostatic interactions which, although relatively weak, results in some conformational differences as compared to oxazole-amino acids.

Our studies have been inspired by naturally occurring, highly structurally modified peptides produced by 


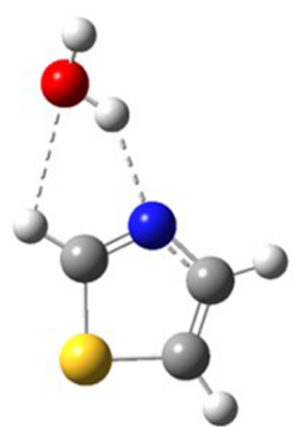

Tzl-N1

$0-\mathrm{H}^{\cdots} \mathrm{N}^{\mathrm{Tzl}} 2.02 ; \Varangle 143.3^{\circ}$

$\mathrm{C}-\mathrm{H}^{\mathrm{Tzl}} \ldots 0$ 2.51; $\Varangle \mathbf{1 0 7 . 1}^{\circ}$

$5.50 \mathrm{kcal} / \mathrm{mol}$ (vacuo)

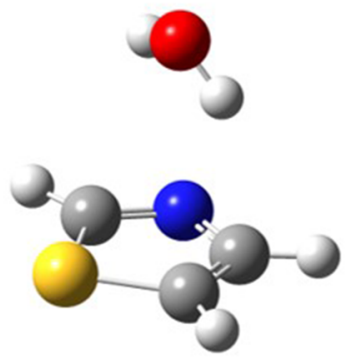

Tzl-N1

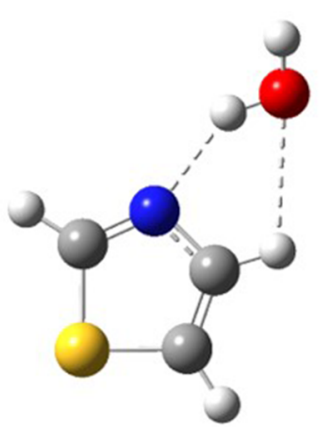

Tzl-N2

$0-\mathrm{H}^{\cdots} \cdot \mathrm{N}^{\mathrm{Tzl}} 2.00 ; \Varangle 146.2^{\circ}$ $\mathrm{C}-\mathrm{H}^{\mathrm{Tzl}} \ldots \mathrm{O} 2.57 \Varangle \mathbf{1 0 9 . 2}^{\circ}$ $5.19 \mathrm{kcal} / \mathrm{mol}$ (vacuo)

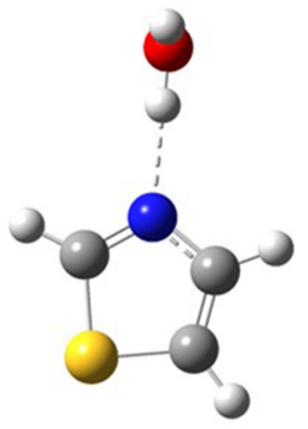

Tzl-N2

$\mathrm{O}-\mathrm{H} \cdots \mathrm{N}^{\mathrm{Tzl}} 1.89 ; \Varangle \mathbf{1 7 6 . 4}^{\circ}$

$1.91 \mathrm{kcal} / \mathrm{mol}$ (water)

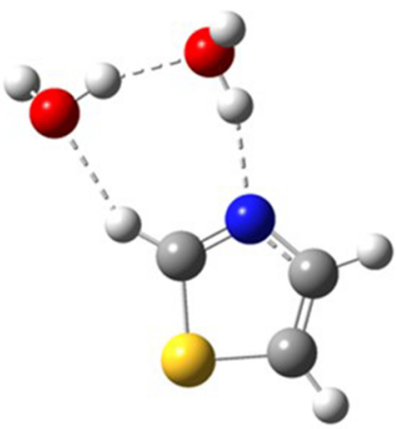

Tzl-N1 $\mathrm{H}_{2} \mathrm{O}$ x2

$0-\mathrm{H}^{\cdots} \cdot \mathrm{N}^{\mathrm{Tzl}} 1.88 ; \Varangle 161.9^{\circ}$

C-H ${ }^{\mathrm{Tzl}} \ldots \mathrm{O} \quad 2.15 ; \Varangle 149.9^{\circ}$

$14.51 \mathrm{kcal} / \mathrm{mol}$ (vacuo)

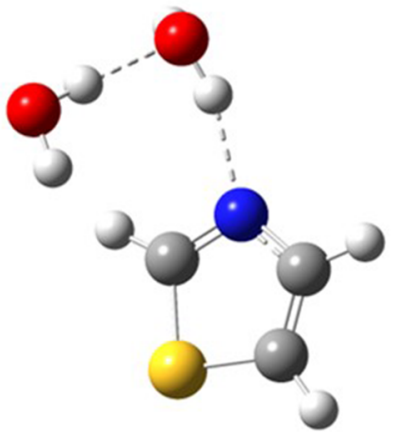

Tzl-N1 $\mathrm{H}_{2} \mathrm{O} \times 2$

$\mathrm{O}-\mathrm{H}^{\cdots} \cdot \mathrm{N}^{\mathrm{Tzl}}$ 1.88; $\Varangle 161.9^{\circ}$

$\mathrm{O}-\mathrm{H} \cdots \mathrm{O} \quad 1.86 \Varangle 177.2^{\circ}$

$4.21 \mathrm{kcal} / \mathrm{mol}$ (water)

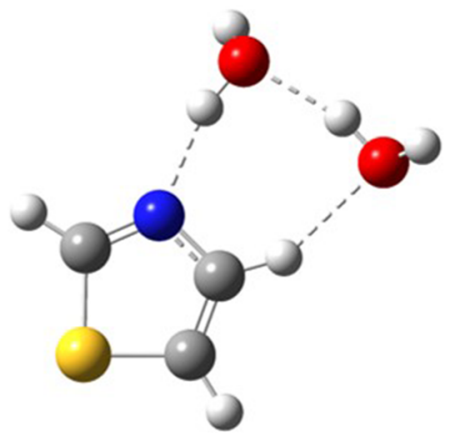

Tzl-N2 $\mathrm{H}_{2} \mathrm{O}$ x2

$0-\mathrm{H}^{\cdots} \mathrm{N}^{\mathrm{Tzl}} 1.89 ; \Varangle 163.1^{\circ}$

$\mathrm{C}-\mathrm{H}^{\mathrm{Tzl}} \ldots \mathrm{O} 2.23 \Varangle \mathbf{1 5 2 . 0}^{\circ}$

$13.48 \mathrm{kcal} / \mathrm{mol}$ (vacuo)

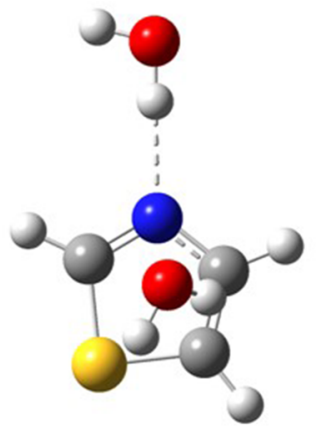

Tzl-N2 $\mathrm{H}_{2} \mathrm{O} \times 2$

$\mathrm{O}-\mathrm{H} \cdots \mathrm{N}^{\mathrm{Tzl}} 1.89 ; \Varangle 179.44^{\circ}$

$2.84 \mathrm{kcal} / \mathrm{mol}$ (water)

$1.45 \mathrm{kcal} / \mathrm{mol}$ (water)

Fig. 8 Water-thiazole ring complexes with interaction energies calculated by M06-2X/6-311++G(d,p) method

microorganisms that differentiated their bioactivities. We believe that our findings may be useful in understanding the bioactive conformations of these natural peptides containing the structural units studied. The unique properties of such non-standard amino acid residues should result in increasing interest and point out the potential application in drug design.

Supplementary Information The online version contains supplementary material available at https://doi.org/10.1007/s00726-021-02974-0.

Acknowledgements This research was supported in part by PL-Grid Infrastructure. Calculations have been carried out using resources provided by Wroclaw Centre for Networking and Supercomputing (http:// wcss.pl), Grant No. 487 Monika Staś was a recipient of a Ph.D. fellowship from a project funded by the European Social Fund.

\section{Declarations}

Conflict of interest The authors declare that they have no conflict of interest with the information contained in this manuscript.

Research involving human participants and/or animals This article does not contain any studies with human participants or animals performed by any of the authors.

Informed consent No informed consent is required for this study.

Open Access This article is licensed under a Creative Commons Attribution 4.0 International License, which permits use, sharing, adaptation, distribution and reproduction in any medium or format, as long as you give appropriate credit to the original author(s) and the source, provide a link to the Creative Commons licence, and indicate if changes were made. The images or other third party material in this article are included in the article's Creative Commons licence, unless indicated otherwise in a credit line to the material. If material is not included in the article's Creative Commons licence and your intended use is not permitted by statutory regulation or exceeds the permitted use, you will 
need to obtain permission directly from the copyright holder. To view a copy of this licence, visit http://creativecommons.org/licenses/by/4.0/.

\section{References}

Abbenante G, Fairlie DP, Gahan LR, Hanson GR, Pierens GK, van den Brenk AL (1996) Conformational control by thiazole and oxazoline rings in cyclic octapeptides of marine origin. Novel macrocyclic chair and boat conformations. J Am Chem Soc 118(43):10384-10388. https://doi.org/10.1021/ja962260f

Aguesseau-Kondrotas J, Simon M, Legrand B, Bantigniès J-L, Kang YK, Dumitrescu D, Van der Lee A, Campagne J-M, de Figueiredo RM, Maillard LT (2019) Prospect of thiazole-based $\gamma$-peptide foldamers in enamine catalysis: exploration of the nitro-michael addition. Chem Eur J 25(30):7396-7401. https:// doi.org/10.1002/chem.201901221

Aliakbar Tehrani Z, Fattahi A (2013) Conformational aspects of glutathione tripeptide: electron density topological \& natural bond orbital analyses. Struct Chem 24(1):147-158. https://doi.org/ 10.1007/s11224-012-0023-1

Aoki M, Ohtsuka T, Itezono Y, Yokose K, Furihata K, Seto H (1991) Structure of cyclothiazomycin, a unique polythiazole-containing peptide with renin inhibitory activity. Part 1 . Chemistry and partial structures of cyclothiazomycin. Tetrahedron Lett 32(2):217-220

Asano A, Doi M (2004) Turn-over of an oxazoline ring induced by chiral change of a folded ascidiacyclamide analogue: Cyclo(IIeD-aThr-D-Val-Thz-IIe-D-Oxz-D-Val-Thz) N, N-dimethylformamide disolvate. Acta Crystallogr Sect Sect E: Struct Rep Online 60(12):o2449-o2451

Asano A, Taniguchi T, Sasaki M, Hasegawa H, Katsuya Y, Doi M (2001) A [beta]-sheet structure formed by C-H O hydrogen bonds between the thiazole rings and amide bonds of a dimeric desoxazoline ascidiacyclamide analogue. Acta Crystallogr Sect Sect E: Struct Rep Online 57(9):o834-o838

Asano A, Minoura K, Yamada T, Numata A, Ishida T, Doi M, Katsuya Y, Mezaki Y, Sasaki M, Taniguchi T, Nakai M, Hasegawa H, Terashima A (2002a) Effect of asymmetric modification on the conformation of ascidiacyclamide analogs. J Peptide Res 60(1):10-22

Asano A, Yamada T, Numata A, Katsuya Y, Sasaki M, Taniguchi T, Doi M (2002b) A flat squared conformation of an ascidiacyclamide derivative caused by chiral modification of an oxazoline residue. Biochem Biophys Res Commun 297(1):143-147

Asano A, Yamada T, Numata A, Doi M (2003) Cyclo(-Cha-Oxz-D-ValThz-Ile-Oxz-D-Val-Thz-) N, N-dimethylacetamide dihydrate: a square form of cyclohexylalanine-incorporated ascidiacyclamide having the strongest cytotoxicity. Acta Crystallogr Sect C: Cryst Struct Commun 59(9):488-490

Asano A, Yamada T, Katsuya Y, Taniguchi T, Sasaki M, Doi M (2005) Conformational restraints induced by modification of configuration of threonine and oxazoline residues in ascidiacyclamide analogues. J Peptide Res 66:90-98

Bagley MC, Bashford KE, Hesketh CL, Moody CJ (2000) Total synthesis of the thiopeptide promothiocin A. J Am ChemSoc 122(14):3301-3313

Bagley MC, Dale JW, Merritt EA, Xiong X (2005) Thiopeptide antibiotics. Chem Rev 105(2):685-714

Bayly CI, Cieplak P, Cornell W, Kollman PA (1993) A well-behaved electrostatic potential based method using charge restraints for deriving atomic charges: the RESP model. J Phys Chem 97(40):10269-10280. https://doi.org/10.1021/j100142a004
Beno BR, Yeung K-S, Bartberger MD, Pennington LD, Meanwell NA (2015) A survey of the role of noncovalent sulfur interactions in drug design. J Med Chem 58(11):4383-4438

Bernhardt PV, Comba P, Fairlie DP, Gahan LR, Hanson GR, Lötzbeyer L (2002) Synthesis and structural properties of patellamide a derivatives and their copper(ii) compounds. Chem Eur J 8(7):1527-1536

Bertram A, Pattenden G (2007) Marine metabolites: metal binding and metal complexes of azole-based cyclic peptides of marine origin. Nat Prod Rep 24(1):18-30. https://doi.org/10.1039/B612600F

Bertram A, Blake AJ, Turiso FG-L, Hannam JS, Jolliffe KA, Pattenden G, Skae M (2003) Concise synthesis of stereodefined, thiazole - containing cyclic hexa- and octapeptide relatives of the Lissoclinums, via cyclooligomerisation reactions. Tetrahedron 59(35):6979-6990

Boehr DD, D'Amico RN, O'Rourke KF (2018) Engineered control of enzyme structural dynamics and function. Protein Sci 27(4):825838. https://doi.org/10.1002/pro.3379

Breydo L, Barnes CL, Gates KS (2002) Two (E, E)- and (Z, E)-thiazol5-ylpenta-2,4-dienones. Acta Crystallogr Sect C: Cryst Struct Commun 58(8):o447-0449

Broda MA, Siodłak D, Rzeszotarska B (2005) Conformational investigation of $\alpha, \beta$-dehydropeptides. $\mathrm{N}$-acetyl-(E)-dehydrophenylalanine $\mathrm{N}^{\prime}$-methylamide: Conformational properties from infrared and theoretical studies, part XIV. J Pept Sci 11 (4):235-244

Broda MA, Buczek A, Siodłak D, Rzeszotarska B (2009) The effect of $\beta$-methylation on the conformation of $\alpha, \beta$-dehydrophenylalanine: a DFT study. J Pept Sci 15(7):465-473

Buczek A, Makowski M, Jewginski M, Latajka R, Kupka T, Broda MA (2014) Toward engineering efficient peptidomimetics. Screening conformational landscape of two modified dehydroaminoacids. Biopolymers 101(1):28-40

Case DA, Babin V, Berryman J, Betz RM, Cai Q, Cerutti DS, Cheatham T, Darden T, Duke R, Gohlke H, Götz A, Gusarov S, Homeyer N, Janowski P, Kaus J, Kolossváry I, Kovalenko A, Lee T-S, Kollman PA (2014) AMBER 14, University of California, San Francisco. https://doi.org/10.13140/RG.2.2.17892.37766

Castro Rodríguez J, Holgado GG, Santamaría Sánchez RI, Cañedo LM (2002) Radamycin, a novel thiopeptide produced by Streptomyces sp. RSP9. II. Physico-chemical properties and structure determination. J Antibiot 55(4):391-395

Chahkandi B, Chahkandi M (2020) A reconnaissance DFT study of the full conformational analysis of $\mathrm{N}$-formyl-L-serine-Lalanine-NH2 dipeptide. J Mol Model. https://doi.org/10.1007/ s00894-020-04382-9

Chahkandi B, Chahkandi M, Ashrafi B (2014) Conformational analysis of $\mathrm{N}$ - and C-terminally protected tripeptide model glycylisoleucine-glycyl: an ab initio and DFT study. Phys Chem Res 2(1):68-75. https://doi.org/10.22036/pcr.2014.3858

Culka M, Rulíšek L (2019) Factors stabilizing $\beta$-sheets in protein structures from a quantum-chemical perspective. J Phys Chem B 123(30):6453-6461. https://doi.org/10.1021/acs.jpcb.9b04866

Culka M, Rulíšek L (2020) Interplay between conformational strain and intramolecular interaction in protein structures: which of them is evolutionarily conserved? J Phys Chem B 124(16):3252 3260. https://doi.org/10.1021/acs.jpcb.9b11784

Culka M, Galgonek J, Vymětal J, Vondrášek J, Rulíšek L (2019) Toward $\mathrm{Ab}$ initio protein folding: inherent secondary structure propensity of short peptides from the bioinformatics and quantum-chemical perspective. J Phys Chem B 123(6):1215-1227. https://doi.org/10.1021/acs.jpcb.8b09245

Cusack RM, Grøndahl L, Fairlie DP, Gahan LR, Hanson GR (2002) Cyclic octapeptides containing thiazole. Effect of stereochemistry and degree of flexibility on calcium binding properties. $\mathbf{J}$ 
Chem Soc, Perkin Trans 2(3):556-563. https://doi.org/10.1039/ B109168A

Davyt D, Serra G (2010) Thiazole and oxazole alkaloids: Isolation and synthesis. Mar Drugs 8(11):2755-2780

Debono M, Molloy RM, Occolowitz JL, Paschal JW, Hunt AH, Michel KH, Martin JW (1992) The structures of A10255B, -G, and -J: New thiopeptide antibiotics produced by Streptomyces gardneri. J Org Chem 57(19):5200-5208

Dennington R, Keith TA, Millam JM (2016) GaussView. Version 6. Semichem Inc. Shawnee Mission KS

Dill KA, Ozkan SB, Shell MS, Weikl TR (2008) The protein folding problem. Annu Rev Biophys. https://doi.org/10.1146/annurev. biophys.37.092707.153558

Ding Y, Ting JP, Liu J, Al-Azzam S, Pandya P, Afshar S (2020) Impact of non-proteinogenic amino acids in the discovery and development of peptide therapeutics. Amino Acids 52(9):1207-1226. https://doi.org/10.1007/s00726-020-02890-9

Doi M, Asano A, Usami Y, Katsuya Y, Nakai M, Sasaki M, Taniguchi T, Hasegawa H (2001) A folded conformation of an ascidiacyclamide derivative: 3-methoxysulfoxide-(2R,3R)-threoninyl desoxazoline-ascidiacyclamide. Acta Crystallogr Sect Sect E: Struct Rep Online 57(11):1019-1021

Dondoni A, Franco S, Junquera F, Merchán FL, Merino P, Tejero T, Bertolasi V (1995) Stereoselective homologation-amination of aldehydes by addition of their nitrones to $\mathrm{C}-2$ metalated thiazoles - a general entry to $\alpha$-amino aldehydes and amino sugars. Chem Eur J 1(8):505-520

Dudkin VY (2012) Bioisosteric equivalence of five-membered heterocycles. Chem Heterocycl Compd 48(1):27-32

Dupradeau F-Y, Pigache A, Zaffran T, Savineau C, Lelong R, Grivel N, Lelong D, Rosanski W, Cieplak P (2010) The R.E.D tools: advances in RESP and ESP charge derivation and force field library building. PCCP 12(28):7821-7839. https://doi.org/10. 1039/C0CP00111B

Engelhardt K, Degnes KF, Kemmler M, Bredholt H, Fjaervik E, Klinkenberg G, Sletta H, Ellingsen TE, Zotchev SB (2010) Production of a new thiopeptide antibiotic, TP-1161, by a marine Nocardiopsis species. Appl Environ Microbiol 76(15):4969-4976

Fletton RA, Humber DC, Roberts SM, Owston PG, Henrick K (1983) Novel rearrangement of a cephalosporin into a trisubstituted thiazole. J Chem Soc, Chem Commun 17:968-970

Frisch MJ, Trucks GW, Schlegel HB, Scuseria GE, Robb MA, Cheeseman JR, Scalmani G, Barone V, Petersson GA, Nakatsuji H, Li X, Caricato M, Marenich AV, Bloino J, Janesko BG, Gomperts R, Mennucci B, Hratchian HP, Ortiz JV, Izmaylov AF, Sonnenberg JL, Williams, Ding F, Lipparini F, Egidi F, Goings J, Peng B, Petrone A, Henderson T, Ranasinghe D, Zakrzewski VG, Gao J, Rega N, Zheng G, Liang W, Hada M, Ehara M, Toyota K, Fukuda R, Hasegawa J, Ishida M, Nakajima T, Honda Y, Kitao O, Nakai H, Vreven T, Throssell K, Montgomery Jr. JA, Peralta JE, Ogliaro F, Bearpark MJ, Heyd JJ, Brothers EN, Kudin KN, Staroverov VN, Keith TA, Kobayashi R, Normand J, Raghavachari K, Rendell AP, Burant JC, Iyengar SS, Tomasi J, Cossi M, Millam JM, Klene M, Adamo C, Cammi R, Ochterski JW, Martin RL, Morokuma K, Farkas O, Foresman JB, Fox DJ (2016) Gaussian 16 Rev. C.01. Wallingford, CT

Gagné D, Charest LA, Morin S, Kovrigin EL, Doucet N (2012) Conservation of flexible residue clusters among structural and functional enzyme homologues. J Biol Chem 287(53):44289-44300. https:// doi.org/10.1074/jbc.M112.394866

Gahan LR, Cusack RM (2018) Metal complexes of synthetic cyclic peptides. Polyhedron 153:1-23. https://doi.org/10.1016/j.poly. 2018.06.030

Ganesan M, Paranthaman S (2020) Studies on the structure and conformational flexibility of secondary structures in amyloid beta-a quantum chemical study. J Theor Comput Chem 19(06):2050014. https://doi.org/10.1142/s0219633620500145

Gil A, Sodupe M, Bertran J (2009) Influence of ionization on the conformational preferences of peptide models. Ramachandran surfaces of $\mathrm{N}$-formyl-glycine amide and $\mathrm{N}$-formyl-alanine amide radical cations. J Comput Chem 30(12):1771-1784. https://doi. org/10.1002/jcc. 21178

Giri Rao VVH, Gosavi S (2016) Using the folding landscapes of proteins to understand protein function. Curr Opin Struct Biol 36:67-74

Groom CR, Bruno IJ, Lightfoot MP, Ward SC (2016) The Cambridge structural database. Acta Crystallogr Sect B: Struct Sci 72(2):171-179. https://doi.org/10.1107/S2052520616003954

Haberhauer G, Drosdow E, Oeser T, Rominger F (2008) Structural investigation of westiellamide analogues. Tetrahedron 64(8):1853-1859

Hruby VJ, Li G, Haskell-Luevano C, Shenderovich M (1997) Design of peptides, proteins, and peptidomimetics in chi space. Biopolymers 43(3):219-266

Hudáky I, Perczel A (2008) Prolylproline unit in model peptides and in fragments from databases. Proteins: Struct Function Genet 70(4):1389-1407. https://doi.org/10.1002/prot.21630

Hudáky I, Kiss R, Perczel A (2004) A nomenclature of peptide conformers. J Mol Struct 675(1):177-183. https://doi.org/10.1016/j. theochem.2003.12.048

Hughes RA, Moody CJ (2007) From amino acids to heteroaromaticsthiopeptide antibiotics, nature's heterocyclic peptides. Angew Chem Int Ed 46(42):7930-7954. https://doi.org/10.1002/anie. 200700728

Ilardi EA, Vitaku E, Njardarson JT (2014) Data-mining for sulfur and fluorine: an evaluation of pharmaceuticals to reveal opportunities for drug design and discovery. J Med Chem 57(7):2832-2842. https://doi.org/10.1021/jm401375q

In Y, Doi M, Inoue M, Ishida T, Hamada Y, Shioiri T (1994) Patellamide A, a cytotoxic cyclic peptide from the ascidian Lissoclinum patella. Acta Crystallogr Sect C: Cryst Struct Commun 50(3):432-434

Ishida T, In Y, Doi M, Inoue M, Hamada Y, Shioiri T (1992) Molecular conformation of ascidiacyclamide, a cytotoxic cyclic peptide from Ascidian: X-ray analyses of its free form and solvate crystals. Biopolymers 32(2):131-143

Jaremko M, Jaremko Ł, Mazur A, Makowski M, Lisowski M (2013) Enhanced $\beta$-turn conformational stability of tripeptides containing $\Delta \mathrm{Phe}$ in cis over trans configuration. Amino Acids 45(4):865-875. https://doi.org/10.1007/s00726-013-1534-9

Jin Z (2011) Muscarine, imidazole, oxazole, and thiazole alkaloids. Nat Prod Rep 28(6): 1143-1191

Jüttner F, Todorova AK, Walch N, von Philipsborn W (2001) Nostocyclamide M: a cyanobacterial cyclic peptide with allelopathic activity from Nostoc 31. Phytochemistry 57(4):613-619

Jwad R, Weissberger D, Hunter L (2020) Strategies for fine-tuning the conformations of cyclic peptides. Chem Rev 120(17):9743-9789. https://doi.org/10.1021/acs.chemrev.0c00013

Kai M, González I, Genilloud O, Singh SB, Svatoš A (2012) Direct mass spectrometric screening of antibiotics from bacterial surfaces using liquid extraction surface analysis. Rapid Commun Mass Spectrom 26(20):2477-2482

Kaiser D, Videnov G, Maichle-Mössmer C, Strähle J, Jung G (2000) $\mathrm{X}$-ray structures and ab initio study of the conformational properties of novel oxazole and thiazole containing di- and tripeptide mimetics. J Chem Soc, Perkin Trans 2(5):1081-1085

Kang YK, Park HS (2014) Conformational preferences of the 2-methylproline residue and its role in stabilizing $\beta$-turn and polyproline II structures of peptides. New J Chem 38(7):2831-2840. https:// doi.org/10.1039/c4nj00072b 
Kang YK, Byun BJ, Park HS (2011) Conformational preference and cis-trans isomerization of 4-methylproline residues. Biopolymers 95(1):51-61

Kheirjou S, Fattahi A, Hashemi MM (2014) The intramolecular cation- $\pi$ interaction of some aryl amines and its drastic influence on the basicity of them: AIM and NBO analysis. Comput Theor Chem 1036:51-60. https://doi.org/10.1016/j.comptc.2014.02.008

Lassila JK (2010) Conformational diversity and computational enzyme design. Curr Opin Chem Biol 14(5):676-682. https://doi.org/10. 1016/j.cbpa.2010.08.010

Le G, Vandegraaff N, Rhodes DI, Jones ED, Coates JAV, Thienthong N, Winfield LJ, Lu L, Li X, Yu C, Feng X, Deadman JJ (2010) Design of a series of bicyclic HIV-1 integrase inhibitors. Part 2: azoles: effective metal chelators. Bioorg Med Chem Lett 20(19):5909-5912. https://doi.org/10.1016/j.bmcl.2010.07.081

Li X, Tu Z, Li H, Liu C, Li Z, Sun Q, Yao Y, Liu J, Jiang S (2013) Biological evaluation of new largazole analogues: alteration of macrocyclic scaffold with click chemistry. ACS Med Chem Lett 4(1):132-136

Mali SM, Schneider TF, Bandyopadhyay A, Jadhav SV, Werz DB, Gopi HN (2012) Thiazole-carbonyl interactions: a case study using phenylalanine thiazole cyclic tripeptides. Cryst Growth Des 12(11):5643-5648

Marsh R (1997) The perils of Cc revisited. Acta Crystallogr Sect B: Struct Sci 53(2):317-322

McDonald LA, Foster MP, Phillips DR, Ireland CM, Lee AY, Clardy J (1992) Tawicyclamides A and B, new cyclic peptides from the ascidian lissoclinum patella: studies on the solution-and solidstate conformations. J Org Chem 57(17):4616-4624

Merino P, Franco S, Merchan FL, Tejero T (1998) Crystal structure of 1-(tert-butoxycarbonylamino)-1-deoxy-2,3-O-isopropylidene-1-(2-thiazolyl)-D-threo-triitol, C14H22N2O4S. Zeitschrift für Kristallographie New Crystal Structures 213

Metelev MV, Ghilarov DA (2014) Structure, function, and biosynthesis of thiazole/oxazole-modified microcins. Mol Biol 48(1):29-45

Murray JS, Lane P, Politzer P (2008) Simultaneous $\sigma$-hole and hydrogen bonding by sulfur- and selenium-containing heterocycles. Int J Quantum Chem 108(15):2770-2781. https://doi. org/10.1002/qua.21753

Nicolaou KC, Nevalainen M, Zak M, Bulat S, Bella M, Safina BS (2003) Synthetic studies on thiostrepton: construction of thiostrepton analogues with the thiazoline-containing macrocycle. Angewandte Chem Int Ed 42(29):3418-3424

Paranthaman S (2018) The effect of intramolecular h-bond interactions in the isomerization process in amino acids. J Chil Chem Soc 63(3):4041-4046. https://doi.org/10.4067/s0717-97072 018000304041

Pettit GR, Barkoczy J, Srirangam JK, Singh SB, Herald DL, Williams MD, Kantoci D, Hogan F, Groy TL (1994) The Dolastatins. 22. Synthesis of boc-dolaproinyl dolaphenine and four related chiral isomers. J Organic Chem 59(11):2935-2938

Pettit GR, Hogan F, Herald DL (2004) Synthesis and X-ray crystal structure of the dolabella auricularia peptide dolastatin 18,1 . J Org Chem 69(12):4019-4022

Reid RC, Yau M-K, Ranee S, Lim J, Fairlie DP (2014) Stereoelectronic effects dictate molecular conformation and biological function of heterocyclic amides. J Am Chem Soc 136:11914-11917

Rose GD, Fleming PJ, Banavar JR, Maritan A (2006) A backbone-based theory of protein folding. Proc Natl Acad Sci 103(45):16623-16633. https://doi.org/10.1073/pnas.06068 43103

Scarsdale JN, Van Alsenoy C, Klimkowski VJ, Schaefer L, Momany FA (1983) Ab initio studies of molecular geometries. 27.
Optimized molecular structures and conformational analysis of N.alpha.-acetyl-N-methylalaninamide and comparison with peptide crystal data and empirical calculations. J Am Chem Soc 105(11):3438-3445

Schärfer C, Schulz-Gasch T, Ehrlich H-C, Guba W, Rarey M, Stahl M (2013) Torsion angle preferences in druglike chemical space: a comprehensive guide. J Med Chem 56(5):2016-2028

Schmitz FJ, Ksebati MB, Chang JS, Wang JL, Hossain MB, Van der Helm D, Engel MH, Serban A, Silfer JA (1989) Cyclic peptides from the ascidian Lissoclinum patella: conformational analysis of patellamide D by x-ray analysis and molecular modeling. J Org Chem 54(14):3463-3472

Seiser T, Kamena F, Cramer N (2008) Synthesis and biological activity of largazole and derivatives. Angew Chem Int Ed 47(34):6483-6485

Siodłak D (2015) $\alpha, \beta$-Dehydroamino acids in naturally occurring peptides. Amino Acids 47:1-17

Siodłak D, Janicki A (2010) Conformational properties of the residues connected by ester and methylated amide bonds: theoretical and solid state conformational studies. J Pept Sci 16(3):126-135. https://doi.org/10.1002/psc.1208

Siodłak D, Gajewska M, Macedowska A, Rzeszotarska B (2006) Conformational studies into $\mathrm{N}$-methylation of alanine diamide models: a quantitative approach. J Mol Struct 775(1-3):47-59

Siodłak D, Macedowska-Capiga A, Grondys J, Paczkowska K, Rzeszotarska B (2008) N-Methyldehydroamino acids promote a configuration cis of N-methylamide bond. J Mol Struct 851(1-3):100-108

Siodłak D, Grondys J, Lis T, Bujak M, Broda MA, Rzeszotarska B (2010) The conformational properties of dehydrobutyrine and dehydrovaline: theoretical and solid-state conformational studies. J Pept Res 16(9):496-505

Siodłak D, Grondys J, Broda MA (2011) The conformational properties of $\alpha, \beta$-dehydroamino acids with a $\mathrm{C}$-terminal ester group. J Pept Sci 17(10):690-699

Siodłak D, Macedowska-Capiga A, Broda MA, Kozioł AE, Lis T (2012) The cis-trans isomerization of N-methyl- $\alpha$, $\beta$-dehydroamino acids. Biopolymers 98(5):466-478

Siodłak D, Staś M, Broda MA, Bujak M, Lis T (2014a) Conformational properties of oxazole-amino acids: effect of the intramolecular $\mathrm{N}-\mathrm{H} \cdots \mathrm{N}$ hydrogen bond. J Phys Chem B 118(9):2340-2350

Siodłak D, Staś M, Broda MA, Bujak M, Lis T (2014b) Conformational properties of oxazole-amino acids: effect of the intramolecular N-H $\cdots \mathrm{N}$ hydrogen bond. J Phys Chem B 118(9):23402350. https://doi.org/10.1021/jp4121673

Staś M, Broda MA, Siodłak D (2016a) Conformational properties of oxazoline-amino acids. J Mol Struct 1109:192-200

Staś M, Bujak M, Broda MA, Siodłak D (2016b) Conformational preferences and synthesis of isomers $\mathrm{Z}$ and $\mathrm{E}$ of oxazole-dehydrophenylalanine. Biopolymers 106(3):283-294

Stezowski JJ, Pöhlmann HW, Haslinger E, Kalchhauser H, Schmidt U, Pozollia B (1987) The conformation of cyclo[1-pro-1-leu-1val-(gly)thz-(gly)thz], a dolastatin 3 analog, in the crystalline and solution states. Tetrahedron 43(17):3923-3930

Todorova AK, Jüttner F, Linden A, Plüiss T, von Philipsborn W (1995) Nostocyclamide: a new macrocyclic, thiazole-containing allelochemical from Nostoc sp 31 (Cyanobacteria). J Org Chem 60(24):7891-7895

Vanquelef E, Simon S, Marquant G, Garcia E, Klimerak G, Delepine JC, Cieplak P, Dupradeau F-Y (2011) R.E.D. Server: a web service for deriving RESP and ESP charges and building force field libraries for new molecules and molecular fragments. Nucleic Acids Res 39(suppl_2):W511-W517. https://doi.org/ 10.1093/nar/gkr288 
Vollbrecht L, Steinmetz H, Höfle G (2002) Argyrins, immunosuppressive cyclic peptides from myxobacteria. II. Structure elucidation and stereochemistry. J Antibiot 55(8):715-721

Walsh CT, Acker MG, Bowers AA (2010) Thiazolyl peptide antibiotic biosynthesis: a cascade of post-translational modifications on ribosomal nascent proteins. J Biol Chem 285(36):27525-27531

Weinhold F, Landis CR (2001) Natural bond orbitals and extensions of localized bonding concepts. Chem Educ Res Practice 2(2):91-104. https://doi.org/10.1039/B1RP90011K

You SL, Kelly JW (2005) Total synthesis of didmolamides A and B. Tetrahedron Lett 46(15):2567-2570

Young TS, Walsh CT (2011) Identification of the thiazolyl peptide GE37468 gene cluster from Streptomyces ATCC 55365 and heterologous expression in Streptomyces lividans. Proc Natl AcadSci USA 108(32):13053-13058

Zhang Q, Liu W (2013) Biosynthesis of thiopeptide antibiotics and their pathway engineering. Nat Prod Rep 30(2):218-226

Zhang C, Herath K, Jayasuriya H, Ondeyka JG, Zink DL, Occi J, Birdsall G, Venugopal J, Ushio M, Burgess B, Masurekar P, Barrett JF, Singh SB (2009) Thiazomycins, thiazolyl peptide antibiotics from Amycolatopsis fastidiosa. J Nat Prod 72(5):841-847
Zhang X, Gong Z, Li J, Lu T (2015) Intermolecular sulfur·oxygen interactions: theoretical and statistical investigations. J Chem Inf Model 55(10):2138-2153. https://doi.org/10.1021/acs.jcim. $5 \mathrm{~b} 00177$

Zhao Y, Truhlar D (2008) The M06 suite of density functionals for main group thermochemistry, thermochemical kinetics, noncovalent interactions, excited states, and transition elements: two new functionals and systematic testing of four M06class functionals and 12 other functionals. Theor Chem Acc 120(1-3):215-241

Zhou X, Huang H, Chen Y, Tan J, Song Y, Zou J, Tian X, Hua Y, Ju J (2012) Marthiapeptide A, an anti-infective and cytotoxic polythiazole cyclopeptide from a $60 \mathrm{~L}$ scale fermentation of the deep sea-derived Marinactinospora thermotolerans SCSIO 00652. J Nat Prod 75(12):2251-2255

Publisher's Note Springer Nature remains neutral with regard to jurisdictional claims in published maps and institutional affiliations. 